\title{
Educação, redistribuição e reconhecimento: contribuições do pensamento de Nancy Fraser para o debate sobre justiça
}

\author{
Swamy de Paula Lima Soares ${ }^{1}$ \\ ORCID: 0000-0001-7489-3698
}

\section{Resumo}

Este artigo discute as contribuições da filósofa e ativista norte-americana Nancy Fraser para o debate sobre redistribuição e reconhecimento, analisando possíveis repercussões na relação entre justiça e educação. 0 debate ora apresentado tem sido um dos mais fecundos nas ciências sociais nos últimos anos, com forte repercussão para as políticas sociais e educacionais. A questão é compreender em que medida as políticas priorizam aspectos mais universais, com foco no conceito de equidade e em seus desdobramentos, ou ações de reconhecimento de identidades, pauta que tem ganhado centralidade, inclusive, nos discursos educacionais a partir do debate sobre gênero. Conhecida pela sua atuação no debate sobre feminismo, Fraser tem como um de seus focos de análise a organização dos discursos e das ações políticas no contexto das lutas nacionais e transnacionais. A partir das contribuições de Fraser, busca-se compreender as tensões deste debate e as perspectivas conciliatórias entre as duas correntes. Ao final, procura-se refletir sobre como redistribuição e reconhecimento influenciam o debate educacional, especialmente no momento social e político contemporâneo. De tendência conciliadora, Fraser aponta a possibilidade de pontes entre ações políticas que valorizem as identidades dos sujeitos e as que fortaleçam lutas históricas ligadas à universalização de direitos e da justa distribuição financeira que, em países como o Brasil, ainda estão longe de serem temas de um passado distante.

\section{Palavras-chave}

Educação - Reconhecimento - Redistribuição.

1- Universidade Federal da Paraíba, João Pessoa, Paraíba, Brasil. Contato: swamysoares@ce.ufpb.br 


\section{Education, redistribution and recognition: contributions of Nancy Fraser's thought to the justice debate}

\section{Abstract}

This article discusses the contributions of American philosopher and activist Nancy Fraser to the debate on redistribution and recognition, analyzing possible repercussions on the relationship between justice and education. The debate presented here has been one of the most fruitful in the social sciences in recent years, with strong impact on social and educational policies. It is all about understanding to what extent policies prioritize more universal aspects, focusing on the concept of equity and its consequences, or actions to recognize identities, an agenda that has gained centrality, including educational discourses stemming from the debate on gender. Known for her role in the debate on feminism, in her analyses Fraser has focused on the organization of discourses and political actions in the context of national and transnational struggles. Based on Fraser's contributions, we seek to understand the tensions of this debate and the conciliatory perspectives between the two strands. Eventually, we seek to reflect on how redistribution and recognition influence the educational debate, especially in the contemporary social and political context. With a conciliatory tendency, Fraser points the possibility of bridges between politcal actions that enhance the identities of subjects and those that strengthen historical struggles linked to the universalization of rights and fair financial distributions that, in countries like Brazil, are still far from being themes of a distant past.

\section{Keywords}

Edcucation - Recognition - Redistribution.

\section{Introdução}

0 debate sobre redistribuição e reconhecimento se mostrou como um dos mais fecundos na teoria social dos últimos quarenta anos. Na base dessa discussão, encontramse temas como as liberdades individuais, as tensões entre igualdade e liberdade, as relações identitárias e a construção do que seria uma boa vida para cada pessoa ou grupo. No caso dos chamados teóricos da redistribuição, temos uma espécie de revisão do liberalismo, a partir de uma profunda reflexão sobre os rumos das sociedades liberais/ democráticas. Na verdade, desde a publicação de Uma teoria da justiça, nos anos de 1970, John Rawls (2002) já revia criticamente um dos pontos centrais de uma série de estudos liberais, a saber: a questão (ou o problema) do utilitarismo. 0 filósofo estadunidense propunha uma estrutura teórica que, dentro de uma espécie de valorização do Estado Democrático de Direito, pudesse sair da armadilha utilitária, armadilha essa que começava a ganhar espaço tanto na teoria social quanto na proposição de ações estatais naquilo que, 
posteriormente, viria a ser a ascensão do neoliberalismo. A proposta de Rawls dava novos significados à tradição clássica do liberalismo do Século XVIII, remontando à ideia de que a competição entre indivíduos, para ter um mínimo de justiça, deveria se fundamentar em uma espécie de ponto de partida. Tal princípio foi chamado pelo autor de igualdade equitativa de oportunidades, e seu pensamento aprofundou os mecanismos democráticos de organização da sociedade com o fito de assegurar a garantia do que Rawls denominou de estrutura básica. No centro do pensamento de Rawls, encontrava-se a ideia de que as democracias não podiam sobreviver em um estado agudo de desigualdades; em outros termos, ainda que as liberdades individuais pudessem criar desigualdades aceitáveis dentro de um modelo social liberal, a atuação dos indivíduos deveria exprimir certo altruísmo no trato da vida pública. Esse altruísmo, longe de ser um ditame do Estado e sim uma ação livre e consciente do indivíduo, sugeria a predominância do princípio do bem comum em relação à razão utilitária, por isso a necessidade de um desconhecimento dos atores sociais das consequências políticas das suas próprias ações. No centro da teoria de John Rawls, dois conceitos passariam a ganhar força: a equidade e a redistribuição.

Paralelo à construção das ideias redistributivas de base liberal, percebemos o desenvolvimento igualmente fecundo daquilo que, posteriormente, seriam reconhecidas como as teorias do reconhecimento ou teorias comunitaristas. Esta tradição, diferentemente da fundamentação liberal de John Rawls, tinha outra matriz, ligada à teoria crítica de base hegeliana. Mesmo considerando a diversidade da tradição teórica, os chamados filósofos comunitaristas ganharam visibilidade no âmbito das ciências sociais analisando disputas que se impunham ao moderno Estado Liberal. Se a luta pelos direitos individuais impulsionou os movimentos identitários, os mesmos não se limitaram à agenda liberal das liberdades; antes pelo contrário. As chamadas lutas por reconhecimento pressionaram em todo mundo a ação estatal para reconhecer e até mesmo promover distinções e particularidades. Não bastaria apenas o reconhecimento dos direitos individuais, mas também uma espécie de reconhecimento social e econômico. Assim, podemos dizer que a tradição comunitarista dialogou de forma tensa com a tradição liberal, na medida em que nasceu no bojo da discussão dos direitos individuais mas não se limitou a estes. Nos dizeres de um de seus maiores expoentes, o filósofo canadense Charles Taylor, o Estado liberal seria cego para o reconhecimento e promoção de uma política da diferença. Essa tensão se apresentaria, portanto, como uma das mais intensas no cenário social dos últimos anos.

0 debate sobre redistribuição e reconhecimento foi um dos temas centrais de reflexão da filósofa, ativista e escritora norte-americana Nancy Fraser. Tendo como uma das principais referências o feminismo, Fraser procura estabelecer, na análise social contemporânea, paralelos que viessem a responder (pelo menos parcialmente) à tensão entre políticas de reconhecimento de identidades e políticas de redistribuição, focadas na ideia de equidade. A tensão entre reconhecimento e redistribuição não é nova, mas vale ressaltar que esse debate se tornou ainda mais intenso, especialmente após as eleições presidenciais dos Estados Unidos em 2016, que elegeram Donald Trump. Esse acirramento se deu por dois motivos. Primeiramente, pela ebulição de movimentos sociais, com participação central do feminismo, como ação de contestação à onda ultra conservadora representada pelo então recém eleito Presidente republicano. A outra face da polêmica refere-se às críticas feitas 
pela própria esquerda liberal sobre como o discurso do reconhecimento e das identidades contribuiu para a derrota eleitoral dos democratas, representados pela candidata Hillary Clinton. Em um dos artigos mais lidos na seção de política do jornal The New York Times, logo após a eleição de Trump, o cientista político e historiador norte-americano Mark Lilla (2016) atribuiu a derrota eleitoral a uma perspectiva excessivamente identitária da esquerda americana, que acabou afastando aqueles cidadãos mais preocupados com problemas objetivos de seu dia a dia - como a política de empregos, por exemplo. Na visão de Lilla, o excesso das políticas de identidade contribuiu para a criação de isolacionismos sociais e um certo distanciamento dos intelectuais da esquerda dos problemas ligados à questões de classe. No campo educacional, o debate ora apresentado coloca-se igualmente como relevante e atual. Não só pelas consequências conceituais sobre o papel da educação nas políticas de redistribuição ou nas ações de reconhecimento, mas sobretudo pelos temas ligados às construções de identidades que são alvo das correntes conservadoras, nos mais variados debates educacionais. Vale lembrar, como exemplo brasileiro, as diversas investidas conservadoras no campo da chamada "ideologia de gênero", com repercussões nos últimos anos para o currículo e os planos de educação, nas mais variadas esferas de poder. Com o objetivo de investigar a contribuição de Nancy Fraser para a compreensão dessas tensões (e, quiçá, a superação delas), retomaremos inicialmente o debate apresentado no início do texto, dialogando com esta autora e procurando fazer pontes com o cenário contemporâneo no Brasil. Uma última observação diz respeito a essa contextualização. Estamos tratando de temas difíceis, devido à sua pujante atualidade. A emergência desse debate nos dias de hoje não nos dá a segurança do fundamento hegeliano como horizonte hermenêutico para a análise dos acontecimentos. Em outros termos, o filósofo alemão nos ensinava que a segurança da análise histórica estava justamente em olhar para o passado e ver uma forma envelhecida de vida. Estamos metaforicamente em outro barco, na ação navegadora de análise imprecisa e cambiante do tempo presente. Nesse desafio, procuramos ter um insistente cuidado para não simplesmente transpor o debate desses autores para o cenário brasileiro, ainda que os fenômenos estudados tenham aproximação no cenário nacional e global.

\section{Nancy Fraser e o debate sobre reconhecimento e redistribuição}

O contexto intelectual de Nancy Fraser no debate entre redistribuição e reconhecimento pode ser entendido como um dos mais complexos: a discussão e engajamento político no feminismo. No texto intitulado "Da redistribuição ao reconhecimento? Dilemas da justiça numa era pós-socialista”, a autora esclarece a questão. Na verdade, há uma tensão central que difere essas duas perspetivas, para além da reconhecida distinção de foco entre políticas universalistas (redistribuição) e políticas focalizadas (uma tendência das chamadas lutas por reconhecimento e pela atuação do Estado nesse processo). A tensão está, justamente, na ideia de que a redistribuição baseia-se no paradigma da igualdade e o reconhecimento no paradigma da diferenciação. 
Mas o caráter bivalente do gênero é a fonte de um dilema. Uma vez que as mulheres sofrem, no mínimo, de dois tipos de injustiça analiticamente distintos, elas necessariamente precisam, no mínimo, de dois tipos de remédios analiticamente distintos: redistribuição e reconhecimento. Os dois remédios pendem para direções opostas, porém, e não é fácil persegui-las ao mesmo tempo. Enquanto a lógica da redistribuição é acabar com esse negócio de gênero, a lógica do reconhecimento é valorizar a especificidade do gênero. Eis, então, a versão feminista do dilema da redistribuição-reconhecimento: como as feministas podem lutar ao mesmo tempo para abolir a diferenciação de gênero e para valorizar a especificidade do gênero? (FRASER, 2001, p. 235).

Antes de apresentar as soluções pensadas por Fraser - que, a meu entender, significam muito mais provocações para suscitar a continuidade do debate do que propriamente respostas fechadas ao tema - há de se aprofundar a distinção desses paradigmas, começando pelas chamadas políticas redistributivas, com base na equidade e justiça.

Como bem observa Fraser (2001), as ações redistributivas remetem a uma tradição que incorporam autores socialistas como Marx e liberais como John Rawls, Ronald Dworkin e Amartya Sen. Vamos nos valer das explicações de Chaves (2007) sobre a concepção de liberalismo. De certo modo, muitos autores não consideram Rawls como um liberal no sentido literal do termo, tendo em vista que suas perspectivas analíticas acabaram sustentando programas políticos ligados ao chamado social liberalismo (como parte das propostas do Partido Democrata nos Estados Unidos). Neste caso, autores como Rawls estariam numa concepção distinta do liberalismo clássico, identificado em parte da literatura anglo-saxônica como intelectuais do chamado libertarianismo. Ora, para além das justas distinções apresentadas por Chaves (2007), o fato é de que a tradição de Rawls ressalta dimensões internas de revisão do liberalismo, especialmente na sua conhecida crítica ao utilitarismo. Portanto, a tradição rawlsiana incorpora elementos clássicos do liberalismo do século XVIII (todos precisam ter condições iniciais de igualdade, por exemplo), renovando esse pensamento para a análise das democracias modernas. Justifica-se, assim, a compreensão nesse texto de que tanto Rawls quanto outros autores que formam a chamada tradição redistributiva inserem-se na tradição liberal ou social liberal. Esta parece ser uma curiosa ponte entre as questões redistributivas e a própria tradição marxista de Fraser.

Considerando os elementos citados, a ideia de redistribuição se fundamenta na atuação da sociedade como um complexo organismo onde as pessoas, agindo de uma maneira racional, livre e de forma associativa, inspiram-se em um certo altruísmo. Sim, a perspectiva de redistribuição pressupõe uma posição do sujeito que o coloque como preocupado com o todo, com o bem público. A máxima da redistribuição é a garantia de uma estrutura básica onde possam ser erguidas as bases razoáveis de uma democracia. Sem isso, a própria estrutura democrática corre risco, por negar os princípios básicos da justiça. No campo educacional, entende-se (seguindo uma tradição que remonta ao próprio Adam Smith) que a oferta de escolarização está dentro desse bem comum, indispensável a qualquer cidadão inserido na complexa teia social² ${ }^{2}$ A máxima da redistribuição, portanto,

2- A referência a Adam Smith nos lembra que, mesmo no liberalismo clássico e na máxima de auto-regulação do mercado como mão invisíve/na sociedade, a educação era vista como algo indispensável às pessoas (pelo menos de forma básica). De certo modo, até mesmo autores neoliberais 
é a igualdade no ponto de partida, em elementos básicos e fundamentais a qualquer cidadão e sociedade. Ainda que a equidade tenha sido o conceito mais propagado do filósofo norteamericano, é na igualdade que se fundamentam os princípios redistributivos. 0 tratamento desigual ao diferente (especialmente aquele que teve menos oportunidades para a atuação livre e concorrencial numa sociedade democrática) tem como fim último a igualdade de oportunidades entre cidadãos. Radicaliza-se, portanto, a máxima da partida (igualdade de condições iniciais), deixando a chegada livre para as dinâmicas sociais razoáveis em uma sociedade plural e democrática. Os críticos dos adeptos da redistribuição alegam que essa perspectiva nega as diferenças, com clara tendência a reduzir os elementos da emancipação social às questões econômicas, colocando a diminuição das desigualdades no perigoso jogo de não consideração das diferenças de grupos sociais que anseiam por reconhecimento. A redistribuição cairia, portanto, numa antiga armadilha universalista, que vê em apenas um aspecto da vida social - como a questão da classe no marxismo - o problema central a ser atacado e que resolveria boa parte das distorções de uma sociedade democrática. Em resumo, para os críticos, a redistribuição seria cega às diferenças.

As chamadas ações e/ou políticas de reconhecimento partem, como destacou Fraser, de um outro paradigma, ligado à diferenciação dos sujeitos. A própria tradição filosófica, ainda que dialogue com princípios liberais (como a defesa das liberdades individuais, por exemplo), tem outra matriz; essa ligada, especialmente, à tradição hegeliana. Reconhecer significa um processo realizado com o outro, repleto de ações de respeito. 0 contrário disso - o não reconhecimento ou o falso reconhecimento, como define Charles Taylor (1998) - tem como máxima o desrespeito individual, como observa Axel Honneth (2003). Nesses termos, há o reconhecimento de identidades no plano pessoal, social e político, assim como há ações de desrespeito igualmente nesses planos. É importante destacar a ênfase dada por Honneth às chamadas esferas do reconhecimento, com suas respectivas ações contrárias de desrespeito. Tais esferas configurar-se-iam nas dimensões do amor, do direito e da solidariedade. Suas respectivas violações se relacionam com os maus-tratos e violações que afetam a integridade física e psíquica, no plano do sujeito; violação pela via da privação de direitos e exclusão, que atingem a integridade social do indivíduo como membro de uma comunidade; e degradações e ofensas que afetam os sentimentos de honra e dignidade do mesmo como membro de uma comunidade cultural de valores. 0 autor argumenta que a produção de um diagnóstico do tempo presente deve ser vislumbrada de baixo para cima, do ponto de vista da experiência dos próprios sujeitos sociais. Honneth procura estruturar sua teoria crítica no processo social de construção intersubjetiva da identidade, tanto na esfera pessoal quanto na coletiva. Dentro desse padrão críticonormativo é que ele vai chamar atenção para as diversas lutas por reconhecimento que caracterizam as sociedades contemporâneas. Em outros termos, Honneth utiliza a categoria do reconhecimento como elemento estruturante para explicar as lutas sociais nas sociedades modernas. 
Se o fundamento da redistribuição é a igualdade, a raiz do reconhecimento é a diferença. É a partir desta - a singularidade da diferença - que o sujeito e os grupos podem se afirmar no mundo. Se o paradigma da emancipação na modernidade - como bem observa Boaventura de Sousa Santos (2001) - se aportou nas narrativas universais de libertação conjunta, a política de diferença se afasta dessa tradição e foca nas capacidades de pessoas e grupos sociais libertarem-se da negação - suscitada em geral pela maioria das suas especificidades, da sua visão sobre o que é bom no mundo. Fraser (2007) destaca que essa tradição dos chamados filósofos comunitaristas tende a privilegiar a análise da ética, àquilo que é visto como um bom caminho para a vida das pessoas. Essa ideia do bem e do que é bom é o que sustenta a não singularidade de caminhos, a justa luta para que as escolhas sejam devidamente respeitadas e reconhecidas no debate público. Os críticos à perspectiva do reconhecimento ressaltam sua tendência ao relativismo cultural, isolamento das lutas sociais (pela ausência de elementos comuns) e excessiva subjetivação das ações dos atores sociais. Isso tornaria inviável, por exemplo, a busca de superação de males comuns, a partir de uma compreensão igualmente comum destes problemas. Seria, portanto, um novo imperativo dos grupos (que muitas vezes negariam a heterogeneidade entre indivíduos) inviável para grandes projetos, problemas e soluções macro-sociais.

0 modelo da identidade é profundamente problemático. Entendendo o não reconhecimento como um dano à identidade, ele enfatiza a estrutura psíquica em detrimento das instituições sociais e da interação social. Assim, ele arrisca substituir a mudança social por formas intrusas de engenharia da consciência. (FRASER, 2007, p. 106).

0 caminho da reflexão intelectual de Fraser consiste justamente em desafiar a tendência de oposição e negação entre as duas tradições citadas. Neste caso, é preciso perceber algumas variações no pensamento da autora que, de forma evidente em alguns textos, têm no reconhecimento o seu principal alvo de críticas. Isso reflete a própria concepção e posição política de Nancy Fraser no feminismo, por exemplo. A autora critica perspectivas que tendem a segregar o movimento feminista, colocando-o em contraposição a outras lutas sociais com alta capacidade de interlocução. Voltaremos ao assunto posteriormente. Agora, cabe-nos explicar a proposta de interpretação que a autora procura fazer sobre as políticas de reconhecimento.

Em primeiro lugar, é importante destacar que Fraser aponta uma falsa distinção entre reconhecimento e redistribuição, expressa na máxima Multiculturalismo versus Igualdade Social. Essa polarização foi estabelecida tanto na academia quanto na ação social de grupos que, de um lado e de outro, militam sobre o tema. Contudo, é nítida a crítica que a autora faz em relação à ligação entre o reconhecimento e uma dimensão ética, no sentido da compreensão do que seria uma boa vida para um ou para outro. Explicando melhor, a autora aponta uma tradição na filosofia política de identificação da justiça distributiva com a Moralität (moralidade) kantiana e o reconhecimento com a Sittlichkeit (ética) hegeliana (p. 104). Ainda segundo a autora: 
Teóricos políticos liberais e filósofos morais deontológicos insistem em que o correto tem prioridade sobre o bem. Para eles, as demandas por justiça estão acima das reivindicações éticas. Comunitaristas e teleologistas retrucam que a noção de uma moralidade universalmente vinculante, independentemente de qualquer ideia de bem, é conceitualmente incoerente. Por preferirem abordagens fundamentadas na experiência moral e abordagens superficiais, eles colocam as reivindicações substantivas de valores comunitários culturalmente específicos acima dos apelos abstratos à Razão ou à Humanidade. (FRASER, 2007, p. 104).

A virada teórica proposta por Fraser para superação dessa suposta dicotomia está, justamente, na reconfiguração do reconhecimento para o campo da moral, ainda que em alguns momentos isso pareça impossível. Fraser parece fazer um diagnóstico da problemática do reconhecimento quando há uma vinculação estreita com os processos identitários. Na medida em que o reconhecimento se baseia em identidades, tende a homogeneizar os próprios grupos que estão em disputa naquilo que Honneth (2003) chamou de luta por reconhecimento. Heterogeneidades e individualidades sofreriam uma espécie de submissão que inibiria os conflitos e disputas de poder que acontecem no interior desses próprios grupos. No caso da autora norte-americana, o feminismo poderia apresentar-se como um caso exemplar. Ora, se for vista como uma questão meramente identitária, o movimento feminista (nas disputas aguerridas com outros interesses e grupos na arena política) pode negar sua própria diversidade interna, deixando de perceber que as identidades, muito menos do que uma aproximação única em torno de pontos em comum, podem ser compreendidas como um todo complexo, repleto de micro interesses e disputas por poder. Isso é legítimo na arena política e não poderia ser minimizado ou desprezado, como propõem alguns adeptos da política do reconhecimento.

Nessa perspectiva, Fraser propõe uma nova leitura para a questão do reconhecimento, não visto como identidade, mas como luta por posições de igualdade na arena social, portanto, como uma espécie de status, na sua concepção. Seria uma virada radical, na medida em que as lutas sociais estariam muito mais no campo do direito e da justiça do que propriamente no campo da identidade. Esse deslocamento potencialmente poderia criar muito mais condições de aproximação das ações de identidade às questões redistributivas, na medida em que poderiam acarretar uma espécie de elo comum entre estas dimensões. Da mesma forma, a proposta diminuiria o peso das questões identitárias que, de certo modo, acabam não reconhecendo as ações dos indivíduos nos movimentos legítimos de disputa de poder no interior dos próprios grupos. Em outros termos, as questões de falso reconhecimento (termo igualmente utilizado por Charles Taylor para identificar as diversas opressões a grupos sociais) não poderiam ser vistas como uma característica psicológica, mas estariam dentro de um quadro de segregação institucional (FRASER, 2017). Contudo, não seria a solução Fraser uma desidratação do próprio fundamento das políticas e ações de reconhecimento? Não estaria a autora reduzindo o reconhecimento a uma questão de paridade participativa?

Fraser tira o reconhecimento do plano identitário para colocá-lo no plano social e político, na arena pública. 0 falso reconhecimento deixa de ser uma não observação das identidades e passa a ser visto como uma negação de alguém (ou um grupo) no direito de expressar, de forma igualitária, sua opinião ou seus valores na arena pública. 
É justamente nessa virada que se encontra sua separação conspícua das visões de Taylor e Honneth. A injustiça não estaria em não reconhecer a identidade, mas em não colocála em igualdade com outras identidades no espaço público, geralmente porque estas (as chamadas identidades minoritárias) estão historicamente subjugadas ao status quo. Usando um exemplo, o problema de não reconhecimento de um casal homossexual não estaria em não reconhecer o entendimento de boa vida que essas pessoas teriam na construção de seus caminhos e identidades no mundo. Seria, diferentemente, não colocá-los no patamar de igualdade de direitos reivindicatórios em relação aos casais heterossexuais, que em geral gozam de posição de dominação no debate público em diversos países (e, da mesma forma, de reconhecimento jurídico).

Ainda segundo Fraser, a observação do reconhecimento como uma questão de status traria o debate público mais para o campo do respeito do que propriamente da estima. Dessa forma, a autora recupera uma distinção que leva a ideia de respeito a ser considerada como algo potencialmente universal, porque estaria no campo do que é justo. Ao contrário disto, a estima é algo do campo privado, porque tem a ver justamente com o conceito de boa vida. Exprimindo um exemplo em primeira pessoa, eu respeito alguém mesmo se eu não gostar ou achar boa determinadas práticas ou escolhas desse mesmo alguém. Ao contrário, eu só estimo alguém se eu for adepto ou admirador das suas práticas e das suas escolhas. Ora, se o debate do reconhecimento for para o campo da estima, dificilmente sairíamos dos aspectos isolacionistas, visto que ele está sob o paradigma do privado. Ainda que Fraser não discuta esse elemento, é importante adicionar uma reflexão de Rawls sobre a arena pública. Nesse sentido, o respeito às individualidades (perspectiva de justiça) deve ter como base o princípio da razoabilidade. Rawls utiliza, para isso, a premissa do liberalismo político de que ações são razoáveis se elas não ultrapassam as fronteiras de anulação/negação do outro, mais ou menos na ideia clássica de liberdade negativa. As ações não devem ser julgadas se são boas ou não, mas se transcendem ou não a razoabilidade da convivência humana em sociedade (minha liberdade termina quando invade ou suprime a liberdade do outro). Ainda que as consequências práticas dessa premissa sejam tensas e conflituosas, parece ser interessante trazê-las à tona ao debate para elucidar o conceito de respeito trazido por Fraser.

Por outro lado, é importante também destacar as críticas que Fraser faz aos teóricos da redistribuição. Muitos deles tratam os problemas sociais como um elemento de ausência de equidade no campo da economia ou do direito. Isso também seria um reducionismo, na medida em que não seriam incorporadas as desigualdades e tensões no campo cultural (como o exemplo que Fraser dá de um banqueiro negro de Wall Street que não consegue pegar um táxi). A alternativa seria, portanto, pensar um conceito ampliado de justiça, que englobasse os elementos culturais presentes nas tensões sociais contemporâneas. A chave para isso seria justamente o que Fraser chama de paridade de participação, e seu construto teórico ganha contornos conciliatórios nesse conceito. Com isso, ela procura tratar o reconhecimento no campo da moralidade (o que é justo), e não no campo da ética (o que é bom).

As questões postas pela filósofa norte-americana sugerem uma última pergunta: caberia ao modelo de justiça (moralidade) em alguns momentos reconhecer as distinções? Essa pergunta foi feita por Charles Taylor a Habermas sobre as limitações do Estado liberal 
para resolução dos problemas de reconhecimento das identidades. Taylor argumentava que o Estado liberal seria um tanto cego para reconhecer as diferenças, justamente por se pautar no primado da justiça e neutralidade (TAYLOR, 1998). A resposta de Fraser a essa questão é de que, em certos momentos, é preciso o reconhecimento das particularidades. Esse seria o calcanhar de Aquiles de seu construto teórico, uma vez que a questão da ética (em contraposição à moral) voltaria a ser pautada no tratamento das questões de reconhecimento. A pergunta central a ser respondida seria como identificar momentos em que as particularidades deveriam aparecer como elemento central do reconhecimento. Fraser estabelece a participação paritária também como parâmetro para julgar essas questões. Dessa forma, ela quer se afastar de uma espécie de relativismo cultural que cairia na armadilha de reivindicar toda e qualquer diferença pelo simples fato desta (a diferença) se justificar em si. De forma contrária, Fraser acaba se aproximando do conceito de razoabilidade de Rawls, apenas colocando-o em outros termos, ou seja, segundo o pressuposto de igualdade de participação. Uma reivindicação de diferenciação seria justa se ela elevasse o requerente ao patamar de participação paritária na arena pública. Dando outro exemplo, poderíamos destacar a polêmica ocorrida na França sobre o uso do foulard por parte de mulheres muçulmanas nas escolas públicas francesas. Sobre isso, observa:

\footnotetext{
Para aplicar essa dupla exigência, vamos considerar a controvérsia francesa sobre o foulard. Aqui, a questão é saber se as políticas que proíbem as garotas muçulmanas de usar véus em escolas públicas constituem um tratamento injusto de uma minoria religiosa. Nesse caso, aquela(e)s que reivindicam o reconhecimento do foulard precisam estabelecer dois pontos: ela(e)s devem mostrar, primeiro, que a proibição do véu constitui um comunitarismo majoritário injusto, que nega paridade educacional a garotas muçulmanas; e, segundo, que uma política alternativa permitindo o foulard não exacerbaria a subordinação feminina, em comunidades muçulmanas ou na sociedade em geral. Somente estabelecendo esses dois pontos ela(e)s podem justificar a sua reivindicação. (FRASER, 2007, p. 130).
}

Percebe-se, portanto, que a construção conceitual de Fraser de aproximação entre redistribuição e reconhecimento é realizada a partir do modelo da moralidade, algo atribuído filosoficamente ao esquadro da redistribuição. Outro ponto a ser destacado se refere à arena pública, centro da análise da autora e parâmetro para o julgamento, inclusive, dos elementos que devem ser particularizados no debate social.

\section{Educação como uma questão de justiça}

Um elemento importante de reflexão são as possiveis contribuições do debate ora apresentado para o campo educacional. Certamente, esse debate apresenta-se como relevante, inclusive em virtude do atual cenário social não só no Brasil, como em boa parte das democracias ocidentais. 0 cenário descrito é concernente à escalada conservadora, que tem na crítica das chamadas políticas identitárias um de seus focos principais. Talvez o termo conservadorismo não seja o mais apropriado para definir o momento contemporâneo, provavelmente pelo reconhecimento intelectual que devemos ter ao conservadorismo como uma doutrina moral, solidificada a partir do século XVIII 
e que tem em Edmund Burke um de seus principais expoentes. 0 que pretendemos aqui é antes uma espécie de estratégia didática. Certamente, podemos melhor definir algumas posições contemporâneas mais como uma espécie de reacionarismo. No caso da educação, essa escalada tem como principal alvo as chamadas políticas de gênero, educação sexual e, em menor escala, as cotas raciais e sociais.

De certo modo, autores como Mark Lilla (2016) tem criticado uma espécie de excesso do discurso identitário nas pautas sociais da esquerda (os liberais de esquerda norteamericanos, geralmente atuantes no partido democrata). Segundo o autor, o aumento no foco das identidades acabou distanciando as pautas progressistas das questões mais gerais, que atingem boa parte dos cidadãos comuns dos países (como a questão do emprego). A forte crítica de Lilla a essas posições sugere que provavelmente o foco nas chamadas políticas identitárias nos discursos e políticas educacionais talvez tenha tido um peso excessivo, que acabou por tirar o foco de questões importantes no cenário educativo.

É importante destacar que Nancy Fraser traz elementos distintos para compreender e superar teoricamente a tensão entre identidades e redistribuição. Esta tensão, podemos dizer, foi aguçada pelas interpretações de Mark Lilla sobre a não priorização de uma política econômica nacionalista em detrimento da globalização (discurso que ajudou na vitória de Donald Trump, no ano de 2016, em Estados cujos eleitores tendencialmente votariam no partido Democrata, como os do Cinturão da Ferrugem). Fraser parte de outro pressuposto, ainda que igualmente crítico a um reducionismo de problemáticas sociais às questões de reconhecimento de identidades. Essa pista teórica da autora foi dada justamente no debate com Judith Butler, em dois textos publicados nos anos de 1990. Como bem observa Bretas (2017), mesmo com pleno respeito à construção intelectual de Butler e reconhecendo que ambas caminham em lutas políticas de superação das estruturas opressoras na sociedade capitalista, Fraser procura superar a visão de supervalorização das questões de reconhecimento como centro dos problemas de opressão contemporâneos, como também do reducionismo desses problemas às questões de redistribuição. Isso não significa, em contraponto, um desprezo a esses problemas, mas impacta em estratégias de compreensão e de mobilização políticas distintas.

Assim, longe de revogar as opressões sofridas por gays, lésbicas e outras minorias sexuais como "meramente" culturais, a autora pretende mostrar que o falso reconhecimento não significa, pura e simplesmente, ser desrespeitado, menosprezado ou desvalorizado nas atitudes conscientes ou mentais de outros. Antes, é ter negado o status de "parceiro integral" nas interações sociais, sendo, portanto, impedido de "participar como um igual na vida social" - não em consequência de uma má distribuição de recursos, senão como resultado de "padrões institucionalizados" de interpretação e avaliação, os quais levam à consideração de alguém como digno ou indigno de respeito ou estima - nas leis, nas políticas de bem-estar social, na medicina ou na cultura pop, por exemplo. (BRETAS, 2017, p. 240).

Nesses termos, o caminho de Fraser não seria o de negação das políticas identitárias (como numa primeira leitura poderia sugerir a estratégia política de Lilla pós eleições de 2016), mas de afırmação plena nas lutas contra a institucionalização do falso 
reconhecimento, que traz como consequência prática a negação do outro como igual participante da vida e da política em sociedade. Essa negação impacta, inclusive, em questões de redistribuição, seja propriamente econômica (baixos salários, maior incidência de desemprego para determinados grupos sociais), seja no menor acesso aos bens sociais (como no caso de menor oportunidade de escolarização e acesso à educação superior, por exemplo). 0 que nos interessa, nesse momento, é perceber os movimentos que implicam no debate educacional entre perspectivas mais gerais, ligadas à ideia de equidade, e os particulares, que poderiam ser identificados como ações de reconhecimento. Nota-se que, no caso específico da educação escolar, percebemos uma dupla atuação dos princípios da justiça redistributiva e das ações de reconhecimento. Por um lado, dificilmente poderíamos tirar o direito à educação do rol de estruturas básicas que configurariam as sociedades democráticas. 0 direito universal à educação escolar está, de forma mediada, nas lutas por redistribuição e dos direitos básicos que tem caracterizado muitas das democracias ocidentais, incluindo o Brasil. Poderíamos até mesmo afirmar que o pilar simbólico que historicamente sustentou boa parte das lutas por escolarização em nosso país durante todo o século XX teve relação com a dimensão de universalização do direito à educação, da estrutura básica em que este se insere. Por outro lado, a escola também tem sido importante espaço de disputas no campo do reconhecimento, especialmente dos grupos sociais por anos considerados outsiders dos currículos e estruturas formais da escola. Encontra-se nesse espectro a disputa em torno do currículo, da educação antirracista, de visibilidade da cultura campesina e indígena e das relações de gênero. Se usarmos o esquema conceitual de Honneth, essas esferas de reconhecimento poderiam ser compreendidas, no campo da educação escolar, tanto na esfera do amor (especialmente quando falamos das instituições educativas da educação infantil), quanto na esfera do direito e da comunidade.

Cabe-nos ressaltar a necessidade, como aponta Fraser, de pensar a educação para além das dualidades entre redistribuição e reconhecimento. Mas o que parece ser o salto teórico para compreender esse debate a partir do pensamento da filósofa norte-americana é que a não dualidade só se sustenta se as duas esferas forem constantemente pensadas em relação. Para isso, cada esfera aparece como uma espécie de contrário fundamental para a sustentação de seu oposto. Não se trata, por exemplo, de criticar as pautas identitárias, possivelmente caindo nas armadilhas conservadoras (como parece ser o risco de teóricos como Mark Lilla), mas de chamar o seu contrário (redistribuição) para pensar o próprio conceito de reconhecimento. Uma ação identitária que não dialogue com os sujeitos reais, inseridos em condições de classe, de violência, de lutas, conquistas, retrocessos e avanços, perde sua própria potência política. A dimensão de redistribuição, nesse exemplo, apareceria como um contrário que levaria às ações de reconhecimento muito mais para o campo da luta emancipatória do que, propriamente, para o campo da cooptação do sistema vigente.

Por outro lado, parece ser inviável voltar a um discurso universalista e exclusivamente redistributivo da escola. Deixar de compreender o campo da educação escolar como um espaço de luta por reconhecimento e visibilidade de grupos e identidades historicamente colocados à margem do campo educacional (incluindo o currículo), seria um retrocesso político e pedagógico inimaginável, com fortes implicações para o próprio campo do direito 
à educação. Logo, aos defensores da escola como espaço de composição da lista de direitos democráticos (campo da redistribuição), caberia invocar o ser contrário (reconhecimento) para compreender que no campo do direito à educação, as lutas por reconhecimento são fundamentais para a consolidação de qualquer projeto razoável de sociedade democrática (assumindo o risco das mais variadas posições políticas que esse termo pode supor).

\section{Considerações finais: para a continuidade da discussão}

As discussões ora apresentadas, que repercutem nos possiveis desdobramentos deste debate para pensarmos as relações entre direito, educação e justiça, podem ser vistas por um outro ângulo, especialmente a partir de algumas outras reflexões desenvolvidas por Fraser. Como vimos, a autora é crítica a uma política de identidades que foque excessivamente na particularidade, a partir do reconhecimento daquilo que é bom (dimensão da ética). Fraser (2001) propõe uma outra abordagem para as questões de redistribuição e reconhecimento, ligadas a uma espécie de radicalidade dos projetos. Ela distingue, portanto, dois movimentos: o de afirmação e o de transformação (ou ainda, remédios afirmativos e remédios transformativos). No caso das políticas de reconhecimento, os remédios afirmativos tendem a firmar identidades e - como efeito negativo - criar movimentos isolados. Os remédios transformativos tendem a ser mais radicais, questionando os fundamentos das desigualdades (de afirmação de uma identidade opressora sobre outra), possibilitando novas formas e novos agrupamentos. No caso das políticas de redistribuição, as ações transformativas vão além das políticas pontuais de combate à pobreza, por exemplo. Elas questionam elementos mais fundamentais do panorama social, ligados aos impostos, às formas estruturais de repartição dos bens socialmente produzidos, dentre outros fatores. Ações transformativas têm maior potencialidade de rearranjo dos espaços públicos, porque radicalmente mexem naquilo que conceituamos como cidadania. Voltando ao tema educacional, não se trata - a partir das reflexões de Fraser - de diminuir ou esconder as questões comumente chamadas de identitárias. Não se trata de recuar nos debates sobre multiculturalismo, por exemplo. Mas sim, radicalizá-los a partir de novos reagrupamentos, incluindo a discussão como necessária para as disputas de poder numa democracia. Parece ser igualmente fecunda a contribuição de Fraser para se pensar, no interior do próprio debate educacional, a pertinência dos chamados remédios transformativos e afirmativos. Ainda que a autora claramente prefira os primeiros, a utilização dos remédios afirmativos pode vê-los como necessários e estratégicos, a depender dos jogos e do espírito do tempo em que se encontram esses debates nos campos nacionais e transnacionais.

Em um importante ensaio após as eleições americanas de 2016, Fraser (2018) analisava a situação a partir do conceito de hegemonia ou, em suas interpretações, de uma crise de hegemonia. Essa crise tinha como base a dinâmica neoliberal que tinha sido hegemônica nos governos democratas (naquilo que ela chamou de neoliberalismo progressista) e persistia no governo Trump, só que dessa vez assimilando uma onda reacionária nas questões dos costumes e dos direitos sociais. Neste sentido, a construção do neoliberalismo progressista assumiu os discursos de identidade, pluralidade e empoderamento das minorias sem, contudo, trazer ao centro da vida pública a questão do 
direito, da redistribuição econômica, do reconhecimento institucional e da participação paritária. A resposta do Trumpismo foi a continuidade de um neoliberalismo econômico (o que talvez explique o revés do candidato republicano no mesmo Cinturão da Ferrugem nas eleições de 2020), aliada a uma postura de restrição de direitos e reacionarismo no campo dos costumes. Fraser identifica, contudo, que estaríamos na fase de uma nova construção hegemônica que deveria, pelo menos em um primeiro momento, basear-se no que chamou de populismo progressista. Nessa perspectiva, as questões identitárias necessitariam ser incorporadas numa perspectiva de direitos e de combate às desigualdades. Possivelmente, as questões educacionais estariam em diálogo com essa nova construção. Para isso, as discussões de identidade e de pluralidade não deveriam estar isoladas de questões como acesso, permanência, participação e direito dos mais variados grupos/sociais. 0 discurso da diversidade, desassociado dessas questões, na visão de Fraser, poderia justamente ser utilizado por uma espécie de neoliberalismo adaptado às causas contemporâneas, que se constituiu como um bloco hegemônico em decadência, mas sem um outro modelo que pudesse substituí-lo.

Em síntese, pensar as questões educacionais tendo como pistas o pensamento de Nancy Fraser requer dois movimentos. 0 primeiro, identificar o aparecimento e também as tensões entre redistribuição e reconhecimento no plano educacional. Como falamos anteriormente, tal questão é cambiante em relação aos diversos aspectos que caracterizam o fenômeno educativo, seja na composição e desenvolvimento de políticas educacionais, seja nas tensões em disputa em torno do currículo, do direcionamento pedagógico das escolas e das tensões políticas que moldam esse campo. 0 outro desafio é pensar a relação entre redistribuição e reconhecimento na perspectiva de superação de dicotomias. Tal superação requer, de certa forma, uma renúncia a qualquer pretensão explicativa e dominante, seja das abordagens de redistribuição, seja as do reconhecimento. As pistas dadas pela filósofa estadunidense levam a esse desafıo teórico. Esse texto procurou defender a ideia de que identificar e pensar os dois conceitos em relação pode ser um caminho para trazer à tona da discussão, inclusive, as consequências políticas da redistribuição e do reconhecimento para o campo da emancipação. Em outros termos, pensar a escola sob o paradigma redistributivo sem considerar a luta por reconhecimento é cair na armadilha de negação das identidades que apenas acentua o discurso pretensamente vitorioso das camadas sociais conservadoras, que disputam o campo educacional a partir da premissa de que a escola deve ser neutra em relação a certas pautas polêmicas. De outro modo, uma luta por reconhecimento desassociada das diversas questões sociais que refletem tensões e desigualdades no plano econômico, social e do direito (entendido, inclusive, em seu aspecto formal) tende a favorecer uma espécie de cooptação das pautas identitárias pela atual fase do neoliberalismo, que tem incorporado certos grupos e reivindicações sob a condição de que não haja processos de maiores rupturas com as novas faces do capitalismo contemporâneo. Esses movimentos combinados podem contribuir para um combate ativo ao neoliberalismo reacionário brasileiro, com construções que reavivam a luta pelos direitos, pela democracia e por uma educação inclusiva em tempos sombrios. 


\section{Referências}

BRETAS, Aléxia. 0 heterossexismo é meramente cultural? Judith Butler e Nancy Fraser em diálogo. Ideias, Campinas, v. 8, n. 1, p. 227-246, jan./jun. 2017.

CHAVES, Eduardo. 0 liberalismo na política, economia e suas implicações para a educação: uma defesa. In: LOMBARDI, José Claudinei; SANFELICE, José Luís (org.). Liberalismo e educação em debate. Campinas: Autores Associados; HISTEDBR, 2007. p. 1-60.

FRASER, Nancy. Da redistribuição ao reconhecimento? Dilemas da justiça numa era pós-socialista. In: SOUZA, Jessé (org.). Democracia hoje: novos desafios para a teoria democrática contemporânea. Brasília: Universidade de Brasília, 2001. p.245-282.

FRASER, Nancy. Do neoliberalismo progressista a Trump - e além. Política \& Sociedade, Florianópolis, v. 17, n. 40, p. 43-64, set./dez. 2018.

FRASER, Nancy. Heterossexismo, falso reconhecimento e capitalismo: uma resposta a Judith Butler. Ideias, Campinas, v. 8, n. 1, p. 277-294, jan./jun. 2017.

FRASER, Nancy. Reconhecimento sem ética? In: SOUZA, Jesse; MATTOS, Patrícia (org.). Teoria crítica no século XXI. São Paulo: Annablume, 2007. p. 101-138.

HONNETH, Axel. Luta por reconhecimento: a gramática moral dos conflitos sociais. Tradução: Luiz Repa. São Paulo: Editora 34, 2003. Título original: Kampf um anerkennung: zur moralischen grammatik sozialer konflikte.

LILLA, Mark. The End of Identity Liberalism. The New York Times. New York, nov. 18, 2016. Disponível em: https://www.nytimes.com/2016/11/20/opinion/sunday/the-end-of-identity-liberalism.html. Acesso em: 30, jun. 2021.

RAWLS, John. Uma teoria da justiça. São Paulo: Martins Fontes, 2002. Tradução de Almiro Pisseta e Lenita Maria Rímoli Esteves. Título original: A theory of justice.

SANTOS, Boaventura de Sousa. Para um novo senso comum: a ciência, o direito e a política na transição paradigmática. 3. ed. São Paulo: Cortez, 2001.

TAYLOR, Charles. A política do reconhecimento. In: TAYLOR, Charles (org.). Multiculturalismo: examinando a política de reconhecimento. Lisboa: Instituto Piaget, 1998. p. 45 a 94.

Recebido em: 30.11.2020

Revisado em: 06.04.2021

Aprovado em: 02.08.2021

Swamy de Paula Lima Soares é Doutor em Educação pela Universidade de São Paulo. Atualmente é Professor Associado da Universidade Federal da Paraíba e coordena o Núcleo DICA - Diversidade, Cultura e Afroeducação. 


\section{ERRATA}

Errata: https://doi.org/10.1590/S1678-4634202147246094E

No artigo Educação, redistribuição e reconhecimento: contribuições do pensamento de Nancy

Fraser para a debate sobre justiça - D0I: 10.1590/S1678-4634202147246094 publicado em Educação e Pesquisa, v. 47, e-location e246094, 2021, por favor, corrigir:

\section{No título, onde se lê:}

Educação, redistribuição e reconhecimento: contribuições do pensamento de Nancy Fraser para a debate sobre justiça

\section{Leia-se:}

Educação, redistribuição e reconhecimento: contribuições do pensamento de Nancy Fraser para o debate sobre justiça

Educ. Pesqui., São Paulo, v. 47, e246094E, 2021.

https://doi.org/10.1590/S1678-4634202147246094E 